\title{
7Emerging perspectives on editorial ethics: An interview with Chris Higgins
}

Liz Jackson

Faculty of Education

The University of Hong Kong

Chris Higgins took on the roles of Editor of Educational Theory, and Editor-in-Chief of the Philosophy of Education Yearbook published by the Philosophy of Education Society, in 2013, after having been an Associate Editor and Book Review Editor for Educational Theory for six years. Higgins worked closely with Nicholas C. Burbules to ensure a smooth transition after Burbules' 22 successful years of leadership of the Educational Theory journal.

As a founding member and co-lead (with Georgina Stewart) of the EPAT Editorial Development Group (EDG), and as a former postgraduate leader of the Educational Theory Discussion Group, I was personally motivated in this editor interview project to provide junior scholars - postgraduate students and early career researchers-with perspectives from 'behind the curtain' of journal production and publication. Journal publication can often be daunting and mysterious to the uninitiated - and it is undoubtedly more so now, with the explosion of venues for publishing (some more and less legitimate than others) catalyzed by digital and online journal production and publication. Indeed, my experience of working with Nick Burbules as his assistant during the period of transition for Educational Theory from paper to digital and online publication allowed me a unique insider view of how social, ethical, and technological dimensions of journal editing are evolving today.

Of course, no two experiences or perspectives of a field are alike, and what makes this collection more valuable to the philosophy of education community is the comprehensive view it provides of editorial knowledge and insight into the field of philosophy of education today. Within the group of editors interviewed for this collection, Chris Higgins is one of the more junior editors, as he has recently taken on a full journal editing role. Therefore, I aimed to capitalize in this interview on the opportunity to explore editorial identity in terms of individual growth and development of new understanding based on more recent experience. Viewing this interview project as a form of editorial education, I hoped Chris could share a perspective that was cognizant of the lived realities faced by junior scholars today in relation to publishing in journals. These realities include increasing pressure to produce research outputs that can pull one away from original creation and collaboration, and the challenge of understanding publishing during a time of tremendous growth and marketization.

In this context, I specifically queried Chris about the role of a journal editor today and the ethical responsibilities of an editor, and I asked him to share practical advice for junior scholars facing imperatives to get their work published in this dynamic era. Although he shied away from giving what we joked about as 'advice to the universe', based on our ongoing professional relationship (I am on the review board for Educational Theory and have been mentored by Chris on past writing projects), his perspective was dialogical, constructive, and pragmatic. This interview is based on our video chat held in September 2014, me in Hong Kong and Chris in Champaign, Illinois.

LIZ: How would you describe the role of a journal editor in philosophy of education? Are there any essential characteristics or qualities that an editor needs? 
CHRIS: There are three roles an editor plays. First, you are a kind of arbiter of the quality of work. Work is coming to you, whether you sought it or not, and your reviewers are giving you input on the work. Nonetheless, you have to use your judgement. So one of the roles is weighing in about whether an argument is really original and coherent, and whether it could speak to anybody other than a small little coterie of scholars. Therefore, one quality you need is 'good judgement'.

What are the qualities that go into good judgement? Ever since Aristotle, we have learned that there is something deep and not just simplistically circular about the view that the person who judges well is a person who has good judgement. The reason why that is not simply a vicious circle is that one of the best ways to know whether someone has good judgement is through watching their judgements. I am not sure how much it really helps to try to list the features of judgement, but I would say that it probably takes a decent writer to know the differences between good and mediocre writing. It takes somebody with a sense of how claims fit together to know whether an argument is coherent. It takes somebody who has read pretty widely to have a feel for whether something is original or a rehash.

I think that most of the people in our field have these qualities, so I am not describing something that is atypical. It should be the result of disciplinary education. Sometimes in education and other disciplines there is the assumption that all you need to do is learn your methods, go get your data, and grab something called a 'theoretical framework'. but you may never actually grow in your judgement. You have this bag of things, but you do not feel the confidence that comes from a disciplinary education, one that keeps encouraging you to read, think, discuss, read, think, discuss. Such an education goes beyond methods to sharpen your understanding of what is at the heart of the matter, of what the key claims are and how they fit together. This takes a mind that has read widely, thought about what she has read, and has a sense of imagination and perspective. So what is needed for the role of arbiter of quality is keen judgement, and that should be the result of a thick disciplinary education.

LIZ: This seems like a relational sort of identity, in that you are part of a community, and the community recognizes you and the qualities needed in journal review and editing.

CHRIS: Yes. An editor should be the kind of person who can enter sympathetically and critically into a wide range of arguments. There is a pretty good way of characterizing a good judge of manuscripts. You can sometimes characterize judgement by what its opposite is, and in this case it has two opposites. One arbiter is the kind who likes everything and is indiscriminate, and another is the kind of person who does not know how to enter into an argument sympathetically. They prejudge it, and will not walk with the author. The qualities of a good editor as an arbiter are the qualities of a good interpreter or reader: somebody who can enter sympathetically into an argument without losing themselves and their ability to pose critical questions along the way.

The second role of an editor is to generate work through conversations. Part of what I do is to identify people doing interesting work in the field, and suggest that they, for example, lead a symposium on their topic. I might facilitate a conversation between two people who do not know each other but both have interesting takes on a topic. I identify who is writing interesting books that might not normally be mailed to the journal for review, and request a copy, to place that person into the conversations occurring in our journal. So the editor is not only an arbiter but a kind of matchmaker: somebody who is trying to create conversation and generate topics and occasions for work. So what are the qualities of that-gregariousness? 
LIZ: Such a role is constructive and very social...it requires people skills.

CHRIS: Yes. So one role of an editor is vetting - quality control. The second role is seeding new work-not just judging work as it comes in. But perhaps the most important role of the editor is helping work to develop further. As the editor of Educational Theory, I read three reviews, and write a letter to the author that synthesizes the key points and offers my own perspective, to push the paper to the next level, wherever it is. I try to make every paper better. As with the role of vetting, the developmental role requires qualities of good judgement, insight, imagination, and rigor. But you must also be able to strike a tone with authors. You have to be able to coach a big name in the field, and give a graduate student encouraging feedback.

\section{LIZ: Has your conception of the identity of an editor changed over time?}

CHRIS: Not really. I did not jump into it. I was the book review editor for Educational Theory and an associate editor for six years. I also edited the Philosophy of Education Yearbook one year, which is somewhat equivalent to one volume of Educational Theory. So I cannot say I am surprised by any particular element of the work, other than the amount of it. The pile of manuscripts never goes down. It can go up, but it never goes down. You are always behind. You read a paper three times once it comes in, to decide if it should go out for review and, if so, to whom. Then you read the paper again after you get review feedback. If you have given an author a contingent acceptance decision, you read the paper once more when they have made the revisions, to see whether they have met the spirit of the criticism. You may read it a fourth or fifth time, for various other reasons. So each paper can represent three to five engagements, and we get well over a hundred manuscripts per year.

LIZ: Certainly this is a great deal of additional work that an editor takes on. In relation to being so busy, do you think being an editor has changed who you are as a scholar? Are there conflicting roles with your other duties and interests and passions for research, versus the work of being an editor-a person who is charged with bringing other people together for research in the field?

CHRIS: Yes, being an editor has changed who I am as a scholar, and I find this aspect interesting. I have never been a fast writer. I may become absorbed in teaching or service for some time, and then prioritize writing after. You might think that editing would be disastrous for someone who works in this pattern, because there will never be extra time for their own writing. But actually this gives me one more weapon against my own perfectionism. Whenever there is time, I start writing, and it may not be what I dreamed it would be, but then I realize that it was a dream to think I would have extra days to work on it, so this is it! So I have become more decisive and less perfectionist.

As a scholar, becoming an editor has also given me more motivation to write at times. You read what everyone else writes, and this motivates you to do your own thing. You are more appreciative of your own creative space, when you finally close your email and open up your own document. You appreciate what a different quality of space that writing time is, when you spend more of your time coaching other people's arguments. So being an editor has given me extra motivation to write and more ruthlessness about time which, given my past experience, is 
good for me. Has it changed the kind of things I write about? It may be too soon to tell. I don't think so, yet. But I could imagine that happening in the future, if certain patters of articles over time convinced me that this topic was more tired, or that one more fresh, than I had thought.

LIZ: What advice would you give to junior colleagues who are invited to edit a journal or a special issue of a journal, or who are interested in developing their career in editing?

CHRIS: Well, as someone who has just recently taken on the role of a journal editor, I am also still reaching out to others for advice, myself. Yesterday, I spoke to someone who had been a journal editor for over a decade for advice on how to streamline things without hurting quality. But maybe I could draw on the advice I give to those who serve as guest editors for Educational Theory. I will give you a specific example. Educational Theory might do a review symposium, where scholars write essays reviewing different books. The guest editor for the symposium may ask me what sort of feedback they should give to the authors of the review essays. I will help them to identify problems with the reviews: 'As you can see, this article had no argument of its own; it just reviewed the three books... This essay had an argument of its own, but it did not adequately explore the books; it did not do justice to the books.' These are the two challenges of a review essay. It is very hard to find that middle ground that develops an independent argument while providing a significant review of the books. 'I think we should push Author A in this direction and Author B in the other way...' That is the sort of conversation I will have with a guest editor. I try to provide them with feedback based on what I have learned about the kind of feedback that is likely to have a positive effect on an author.

A guest editor I work with may sometimes share with me the letter they draft to an author before sending it, and I may say, 'You are not pushing them enough, or 'That seems a bit harsh', or 'That is not specific enough to be helpful'. I try to guide them to work with reviewers' comments in drafting letters to authors so that the letters highlight the most important aspects of the reviews, and encourage the authors to appreciate and respond to the concerns within the reviews. Of course, an editor or guest editor can also make their own points, as well. So I may closely coach guest editors on the practical and communication skills involved in editing, while they engage in their work.

Similarly, if a junior scholar asked me about becoming an editor, I would give advice that started with practicalities. Where are you in your career path? Can your dean offer you material support in the form of course releases or graduate assistants? Do you have a firm understanding with people in your department who are going to be on the tenure and promotion committee that this form of leadership of a scholarly field is truly valued? If you do not have, in writing, some very good statement or some precedent in your department, where people were rewarded for being editors, then you should think twice. If what matters to you is earning tenure in one period of your life, or becoming a full professor faster, and your department does not adequately respect editing work or sees it simply as a form of service, then you should think twice, because editing requires a ton of time.

My second round of advice would be at the individual level. It is hard to formulate advice for junior academics in the abstract, but it would be about things like finding your voice as an editor, so that you are entering into an author's work dialogically to make it better. It would be about how you have not only a right but a duty to push authors. You have to find your confidence and find your voice, so that you are not treating authors like students, but neither are deferring to them. One piece of entering into an editing role is realizing that you have to give bad 
news to people. For a certain kind of personality, mine included, that is not fun. Perhaps some people have thicker skin, and do not really care what people think about them. As Nick wrote in his recent essay (Burbules, 2014), a major part of taking on the role of a journal editor is accepting that you are going to be rejecting people. You are going to be viewed at times as a gate keeper, and some people may say that you are keeping the gate the wrong way, for the wrong reasons. It is a position of power even though, as Nick points out, it is somewhat unclear how far that power goes. You do not control what you get, and the reviewers often dictate the main line of response. So while it is not an all-powerful position, it is a position of perceived power, and that impacts the way people interact with you. If you want to become an editor, you should be ready for that.

LIZ: When I recently wrote a book review for Educational Theory, I certainly found it productive and encouraging to receive feedback from you, to better understand your view of what constitutes a balanced review.

This leads into my last question related to the professional ethics of being an editor. Do you think there is a unique set of professional ethics for journal editing, and do you see the editor as a powerful gate keeper, or do you think that idea is exaggerated?

CHRIS: A journal editor in our field has some power to shape the field and effect people's careers. Therefore, an editor has a serious responsibility to make sure work that they make decisions based on the qualities of work, and not based on other factors.

It would not be hard for an editor to send a paper to a certain reviewer to see that it got a particular kind of review, positive or negative. Some reviewers tend to like certain things more than others, and I know that. Some reviewers tend to like most things. Some reviewers tend to reject almost everything. As an editor, you know your reviewers. You may therefore read their reviews with a grain of salt. Yet you must also strive to choose a set of reviewers for an article submission that you think will bring out the genuine strengths and weaknesses of the article. As an editor, if you wanted to prejudge a paper, and you wanted to launder that decision through the review process, you could do it. So if you had personal vendettas against people, it would not be hard to block them from publishing in your journal. Therefore, we hope that in any healthy field people who are editing journals are surrounding themselves with good reviewers, and making decisions based on the quality of the work.

There are all sorts of other, very specific ethical things that come up. For example, if you want to ask an author whether they want to respond to a book review, first you must check with the author of the book review whether they mind having their work shared pre-publication. You cannot just send someone's manuscript out to others without their permission. Authors entrust their manuscripts to you, and they would like to publish them with you, but it is their intellectual property. Until we produce a final version and the author signs the copyright, we must protect their privacy. This is just one example of the many, relatively minor and fairly intuitive as they are, issues that editors have to worry about. But let's consider a bigger issue.

One of the things I admired about the way Nick [Burbules] ran Educational Theory was the way he encouraged methodological pluralism. The field of philosophy of education is very pluralistic, and I appreciate how Educational Theory-and not only Educational Theory, but also other journals in our field - make a point to not pick one side in debates over methodology. As the current editor of Educational Theory, I always try to ask myself: Is my reaction to a submission based on the fact that I might prefer another tradition of thought more? I also try to 
ensure that the review board for the journal represents an incredibly wide range of types of philosophy of education, because I love that tradition in Educational Theory. Matthew Hayden (2012) conducted an empirical study of what gets published in philosophy of education journals. It compares the content of articles published in EPAT, Educational Theory, The Journal of Philosophy of Education (JPE), and Studies in Philosophy and Education (SPE), to identify which journal published the most articles on John Dewey [SPE], or whether JPE is more likely to publish an article on liberal philosophy of education [it is], while Educational Theory is more likely to publish an article on postmodernism [it is, but most postmodern references are found in EPAT]. One of Hayden's findings (2012, p. 25) was that Educational Theory was the least likely to be dominated by a single topic [concept or category of educational philosophy research]. We are proud of this, because it suggests that we at Educational Theory are particularly averse to chasing trends or promoting a certain camp of thinking. Rather, we are trying to keep the pluralism of the field alive. That is another example of the ethic of an editor: you care about the field. So you have to ask yourself: Is the way I am doing the work of editing conducive to the health of the field, or have I slipped into bad habits, where I am tending to rush to judgement, or surrounding myself with an echo chamber?

Another aspect of editing related to professional ethics is that as an editor, you often need to turn to other people in the field for expertise. However, the people whose expertise you know are the people you know. And this is where the danger of the echo chamber comes in. For example, I recently had a paper on Bildung submitted to Educational Theory. However, on my Editorial Review Board, I did not have three appropriate, available reviewers. So I thought about who works on Bildung, and several names came immediately to mind. However, they are also the four people who I know well, who work on Bildung. So then I took an hour, and examined articles about Bildung over the last twenty years, and developed a much longer list of possible reviewers. Sometimes regular reviewers emerge from invitations for ad-hoc reviews in cases like this, and regular reviewers are also more likely to pitch a special issue, or submit an article. Therefore, I want to make sure that I invite people to be a part of the journal beyond those people I most often bump into in my circles. Identifying new people takes some work, so thinking outside your existing professional circles is another ethical aspect of doing this job.

LIZ: As you note, certain reviewers are more positive or more negative than others. Is there a way you can engage reviewers about their tendencies, or a way for reviewers to develop themselves? Or do you think this is just the way people are?

CHRIS: You do see patterns. Somebody came up to me at a conference recently. He was a new reviewer, and asked me for feedback about whether his reviews were helpful and the kind of reviews that I want. I have been on the other end of that, myself. It takes an incredible amount of work to read and to write these mini-essays. As a reviewer, you often wonder how your work was received. So I think some people would be open to a conversation like that, since they put so much time into reviews.

LIZ: Examining the influence and ethical responsibilities of reviewers is perhaps a different angle for thinking through these issues of journal editorial and publication ethics, given that reviewers also play an important role. 
CHRIS: Absolutely. Peer reviewers are shaping the field every bit as much, if not more, than editors. There are some reviewers that I might wish would be a little tougher or more open minded. There is no traditional format for having that kind of editor-reviewer conversation. What I currently do-and I hope this is true of every editor, and it is true of every paper I review-is primarily examine the reasons the reviewer gave me for their review decision rather than consider the disposition by itself [i.e. accept, reject, revise and resubmit, etc.]. If a reviewer decides that a paper should be revised and resubmitted, it matters to me. But I do not just take an average of reviewer decisions in making my choice. Sometimes one reviewer will recommend that a paper is contingently accepted, while another reviewer will recommend a revise and resubmit. I then read the first reviewer's criticisms, and I may find that their concerns about the paper are more serious and severe than those of the second reviewer. Everyone has a slightly different scale. So I do not focus primarily on the disposition. I look closely at the reasoning in the reviews. If a reviewer states that a paper's argument is not as original as the author thinks, I return to the author's paper, and I try to understand the reviewer's perspective and make my own judgement. If I understand the reviewer's concern and agree that there is a problem with originality, I hold the author to that and ask them to deal with the problem. This model of decision-making goes well beyond simply identifying reviewers as being easy or hard. I make decisions based on the reasons reviewers give me, and those reasons become lenses. So I read a paper with four sets of eyes every time, and that is very helpful. I have my own set of eyes, and three other sets of eyes. For example, I see that Liz Jackson found the paper too unclear in parts, so I take a look at the prose and find that it is indeed full of jargon, with some paragraphs being too dense. Through a reviewer, an editor gets another lens through which to read a paper, although ultimately it is the editor's judgement as informed by reviewers, rather than a voting process of reviewers.

LIZ: You have four different voices on what constitutes publishable work, as well as four different schemas about gate keeping of the field. As a reviewer, when I consider whether a journal submission is publishable or not, I may also think about what I want to see in print, what is fair, and my own ethical responsibility to have an open mind about ideas that are new to me. Each reviewer is going through this process of trying to be ethical and open minded, while holding onto a vision of rigor, and each person in the process is going to have a slightly different perspective on these issues.

CHRIS: Absolutely. It can be subjective. As an editor, you can also see instances where a paper troubles a reviewer. Perhaps they feel competitive about it, if their work is related to it. That does not mean that their insights are bad, but you can observe that they are upset. They state that the paper has five major flaws and four medium ones, and they write a paragraph about each. When you identify this, it does not mean that you discount what they say, but you weigh it differently, and perhaps edit it when responding to the author with your decision. So yes, every reading of every paper is a little different. Sometimes reviewers will discount a submitted paper, because it is different from what they do, and they suggest that it is not worth doing. But I have also seen some people discount something because it is too close to what they do, so they put the bar much higher. The same patterns can also go in the reverse: Some reviewers will read a paper that is outside what they do, and they will give it a free pass. You can never quite tell in advance how a review process will conclude. 
LIZ: One more question: What do you think about open-access versus traditional publishing?

CHRIS: Today we have a problem where non-open-access publishing and big publishing companies are charging libraries high rates for subscriptions to journals or bundles of journals, while library budgets are getting cut. If libraries are forced to buy expensive bundles of journals they have fewer funds to buy monographs. That hurts tenure and promotion for scholars who are seeking university presses for publication contracts. Academic publishing is a kind of ecosystem, where the conglomeration of multinational companies publishing books and journals results in much academic work being accessible only if libraries subscribe. In this context, I have sympathy for the open access movement. It feels wrong to lock up ideas behind a firewall and charge a fee for them. At the same time, academic publishers need a financial plan. If you want to use an open-access publishing model, you have to face the costs of running a journal.

Educational Theory supports graduate students. Right now I have one graduate student assistant who works for the Philosophy of Education Yearbook [published by the Philosophy of Education Society], as well as two graduate student assistants for Educational Theory. We also have a managing editor who reads every word of every manuscript multiple times, and the quality shows. That is in addition to the proofreader for Educational Theory from Wiley. Someone like our managing editor requires a salary. I also get a course release, which costs my department money. I get a summer salary, so I do not have to teach and edit at the same time, which costs the journal money. If Educational Theory went open-access rather than publishing with Wiley, how would we pay for all of that? When it comes to open-access publishing models, these are the kinds of things I think about. Our solution has been to not be open-access, but we make a point of keeping our subscription rate very low in comparison to other philosophy of education journals. Average subscription rates for philosophy of educational journals span a stunning range. I am not saying that it is bad to charge more. Some journals are owned by professional societies, and the money goes into the professional society. That is a good thing for the professional society. So these are complicated questions. Our solution so far is not openaccess, but we continue to keep subscription prices down.

LIZ: Speaking of your graduate students, the Educational Theory Discussion Group partly inspired the EPAT Editorial Development Group, as I found participating in the former to be quite illuminating when I was just learning about the field. Perhaps in the future, the two groups can collaborate to systematically explore reviewing, or the future of journal publishing.

CHRIS: I like the idea of ongoing collaboration. I share your desire to let people behind the curtain, so to speak. There is a lot of guesswork for graduate students and junior scholars. You submit a manuscript, and you do not quite know what it means when you get a certain kind of letter in response. An activity or approach that enables young scholars to put on the other hat [as a reviewer or editor] gives them a whole different way of looking at their own work later. If you are continuing that sort of thing with the EPAT EDG, that is wonderful.

LIZ: Thank you for your time. (End of interview.)

Chris Higgins offers a perspective on journal editing that is fresh and dynamic, as a recently appointed journal editor who continues to work to improve routines to increase efficiency 
without harming quality with the support of colleagues. As such, this view from the first few miles of the marathon illuminates everyday aspects of editorial practice that make up the contemporary editorial role. In some sense, these aspects are not too far removed from normal scholarly practices, from the perspective of an author or reviewer. Good judgement, a productive and collaborative spirit, and an orientation toward rigor and continuous improvement should be qualities we strive for when producing our own work, or working with others as colleagues or reviewers. Yet from an ethical perspective, this is demanded of an editor for the health of the field in a more substantive way at the level of every day practice. Receiving 130 manuscripts per year, most of which demand dozens of professional interactions with reviewers and authors, editing requires a tremendous amount of energy and responsibility that would otherwise be spent on other aspects of one's own career development. One has to accept a duty of rejecting colleagues as an essential part of the role, while also reflexively querying one's own assumptions on a continuous basis, to go beyond the confines of existing professional networks and promote pluralism. It would seem that a restless spirit might also be required for this continual field shaping and gate shifting, given that an editor cannot control for the work received, or review dispositions and subjectivity.

Relatedly, Chris's practical perspective on the identity and ethics of an editor leads to highly pragmatic advice for junior scholars who might want to become editors in the future. At a time when research output is emphasized over service commitments in the academic profession, Chris articulates that becoming a leader in a field through editing can compromise one's personal professional trajectory in terms of promotion through the traditional academic ranks. Seeking out experienced mentors and working with current editors is also essential for those taking on smallscale editorial projects (i.e., special journal issues), as much of the work requires effective editorial communication and the development of a constructive and critical voice. Entering into an author's work with appropriate sympathy but high expectations is another unique skill of the role that marking student papers or other mentorship roles cannot fully prepare one for.

As an early career researcher curious about editing work but also naturally interested in my own personal professional advancement, this project has in some ways intimidated me, impressing upon me the tremendous personal commitment on an everyday basis of journal editing. In a line of work that traditionally rewards introverted people who enjoy closing their office doors and opening up their own documents, the attention to detail and interpersonal communication would be very mentally taxing at times for many of us. Being on the front lines of decision-making against a backdrop of the explosion of new process, production, and publication models in academia, an ethical editor must strive for personal, interpersonal, and field-level commitment and integrity, while the papers never stop coming in.

My interview with Chris thus sheds light on the need for collective thinking not just about editorial and review processes and decision-making for the future among junior scholars, but also about ways to defend an ethical view of the academic journal editor in the future, despite the rising tide of market-based publishing models and output-oriented tendencies in academic tenure and promotion practices today. Although Chris discusses decision-making around taking on an editorial role primarily in terms of university agreements, the health of a field as seen via the integrity of its editors is also influenced by other actors, including academic publishers and academic libraries navigating ongoing budget cuts around most of the world. Examining journal editing as an ethical practice in this broader material context is also vital for junior colleagues developing today. 
I thank Chris for his unique perspective and willingness to allow me to enter his own professional world for the development of academic editorial education.

\section{References}

Burbules, N. C. (2014). Philosophical reflections on editing. Educational Theory, 64, 317-331.

Hayden, M. J. (2012). What do philosophers of education do? An empirical study of philosophy of education journals. Studies in Philosophy and Education, 31, 1-27. 